\title{
Information Technologies as a Means of Acmeological Influence in the Context of Personal Self Realization
}

\author{
Balynin I.V. ${ }^{*}$ Nizhneva N.N. ${ }^{2}$, Mikhaylova A.G. ${ }^{3,4}$ \\ ${ }^{1}$ Financial University under the Government of the Russian Federation, Moscow, 125167, Russian Federation \\ ${ }^{2}$ Belarusian State University, Minsk 220030, Belarus \\ ${ }^{3}$ Sevastopol State University, Sevastopol, 299053, Russian Federation \\ ${ }^{4}$ Nakhimov Black Sea Higher Naval School, Sevastopol 299057, Russian Federation \\ *Corresponding author. Email: igorbalynin@mail.ru
}

\begin{abstract}
The problem investigated in this article is important for the professional education system, since changes in the higher education system have made some corrective in to the process of professional training of future specialists during the transition to distance learning in order to prevent the threat of potential infection with a new coronavirus infection, which is associated with person's socio-psychological adaptation to the new social conditions of existence. Therefore, the purpose of this work is to analyze information technologies as a means of acmeological impact in the context of self-realization. Scientific and methodological recommendations and conclusions are obtained on the basis of the theoretical analysis of future persons' socio-psychological qualities, which provide improving the effectiveness of the adaptation process in the transition to distance learning. The reliability and validity of scientific results obtained in the course of the study is based on the implementation of a set of mutually verifying and complementary methods, which are determined by the clarity of methodological principles. The results of the study give possibility to monitor the positive dynamics of the process of person's socio-psychological adaptation to new social conditions of existence within the framework of self-development. Information technologies are defined as a means of acmeological influence on the process of personal development.
\end{abstract}

Keywords: coronavirus infection, distance learning, self realization, information technologies, acmeological approach, socio-psychological qualities

\section{INTRODUCTION}

Changes in the higher education system during the transition to distance learning in order to prevent the threat of potential infection with a new coronavirus are associated with the socio-person's psychological adaptation to the new social conditions of existence. These transformations are aimed at adapting the educational process to the student's personality needs, as well as to new conditions and requirements, which are based on the active environment development, its change and creation of the necessary conditions for successful activity.

Analyzing the success of person's socio-psychological adaptation in the new conditions of existence, it is necessary to differentiate the criteria depending on the group or individual aspect. As indicators of productivity of adaptation at the group level are the following: positive social identity, satisfaction with relationships with a new environment; among the criteria for adaptation at the personal level are: high activity, satisfaction with the meaning of life and an optimistic assessment of the life situation; actualization of developed needs for self- actualization; satisfaction with professional activities as the most important condition for the need realization for self-actualization and emotional stability [1].

The dynamism of social relations causes significant changes in all spheres of human activity (in education, professional activity). Socio-psychological adaptation is not presented as a process of passive adaptation to the new environment, but as an active process of transformation and self-development, so adaptation should be considered in the traditions of the acmeological approach. In this regard, the study of the problem of socio-psychological adaptation of the individual to new, constantly changing realities becomes fundamentally important in theoretical and experimental research.

Significant results can be achieved when applying to practical activities based on the theoretical and methodological basis through feedback from leading scientists to solve problematic non-standard situations. This approach makes the practice-oriented direction of training engineers as the main component of the entire learning process at the university. 


\subsection{Related Work}

The most authoritative studies are the acmeological research of A.A. Derkach, V.G. Zazykin, N.V. Kuzmina, A.A. Bodalev, V.I. Panov's works about a model of the educational environment, which must meet psychodidactic and ecopsychological principles: it is not only the creation of conditions for socialization and development of subjective, and personal qualities and individuality of the learner but also the implementation of environmentally friendly educational technologies "in the sense of their conformity with the natural, physiological and psychological, and social characteristics and patterns of age development of students" [2, p. 71].

However, in the conditions of transformation to a new educational environment, there is a problem of searching effective means of forming communicative readiness, which is an important quality of successful professional interaction. First of all, it is necessary to consider the conditions for successful socio-psychological adaptation of the training person. Therefore, the problem of this research is the following: what are the effective means of selfdevelopment.

Theoretical analysis of psychological and pedagogical literature has shown that the means of effective selfdevelopment during the transition to distance learning was not the subject of special research. Therefore, the purpose of this work is to determine the conditions for successful socio-psychological adaptation of the student's personality in order to further self-development by means of acmeological approach.

To achieve this goal, the following tasks are set: to establish the features of socio-psychological adaptation of the individual in the new conditions of existence that affect the success of the adaptation process; to consider information technologies in the self-development effectiveness

Thus, the sociological analysis of adaptation processes is presented in the works of V.I. Panov, V.V. Gritsenko, A.G. Maklakov and others. The works of L.S. Vigotskiy, A.V. Mudrik, A.V. Petrovsky, A. A. Rean and others are devoted to the social activity of the individual and its role in social adaptation.

Since socio-psychological adaptation is presented as a process to a new reality, educational environment, it is necessary to consider the most significant works on the problem of creating effective conditions for successful person's socio-psychological adaptation during the transition to distance learning. V.I. Panov characterizes the educational environment as the system of "pedagogical and psychological conditions and influences that create an opportunity for the disclosure of as yet undeveloped interests and abilities, and for the development of already manifested abilities of the individual", taking into account the available natural inclinations and requirements of agerelated socialization [2, p. 71].

To determine such pedagogical and psychological conditions, we considered the acmeological researches by A.A. Derkach, A.A. Bodalev [3], A.A. Rean [4], J. Limoges, K. Jagos [5], R. M. Shaminov [6] and others, since the tasks of acmeology are to study the regularities of achieving acme, identifying conditions, factors, and means that contribute or hinder the achievement of peaks in development, self-realization.

Digital information technologies were considered by S. Ahuja, D. Yadav [7], Y. Tabesh [8], E. Howell [9], N. Kucirkova, T. Cremin [10], L. McNeil [11], J. Sargent, A. Casey [12], C. Blundell, S. Nykvist [13]. The role of information technologies in the different spheres of life was analyzed by M. Dorofeyev, M. Kosov, V. Ponkratov, A. Masterov, A. Karaev, M. Vasyunina [14], V.A ,Slepov, V.K. Burlachkov, T.P. Danko, M.E. Kosov, I.I. Volkov, O.A. Grishina, V.D. Sekerin [15].

\subsection{Our Contribution}

This paper presents some improvements based on the acmeological influence in the context of personal self realization [3] during the transition to distance learning in order to prevent the threat of potential infection with a new coronavirus infection, which is associated with person's socio-psychological adaptation to the new social conditions of existence. Scientific and methodological recommendations and conclusions are obtained on the basis of the theoretical analysis of future persons' sociopsychological qualities, which provide improving the effectiveness of the adaptation process in the transition to distance learning.

\subsection{Paper Structure}

The rest of the paper is organized as follows. Section 2 introduces the research methodology used in this paper. Section 3 presents results of the study and discussion of ones. Then section 4 concludes the paper and presents direction for future research.

\section{BACKGROUND}

In order to achieve this goal, we used complementary theoretical research methods: analysis of philosophical, sociological, psychological, pedagogical, social, engineering literature on the problem under consideration; analysis of documentation on the organization of the educational process at the University for the theoretical justification of the essence, functions, indicators of communicative readiness, analysis, synthesis and systematization of the main approaches. On the basis of theoretical analysis of socio-psychological qualities of the future engineers received scientific guidance and insights that improve the efficiency of the process of formation of communicative readiness of future engineers in high school.

The degree of socio-psychological adaptation is determined by the adaptive resources of the individual and the characteristics of the specific environment in which the 
basic needs of the individual are met in a positive attitude, which is possible only if the results of the individual's activity meet the requirements of society. Adaptive resources of a person are represented by sociopsychological and individual characteristics that determine the adaptation level in specific social conditions.

We identify the following indicators of productivity and effectiveness of adaptation: positive social identity, satisfaction with relationships with a new environment; high activity, satisfaction with the meaning of life and an optimistic assessment of the life situation; actualization of developed needs for self-actualization; satisfaction with professional activities as the most important condition for realizing the need for self-actualization; emotional stability.

The choice of research methods is determined by the nature of research tasks. The research strategy was based on an acmeological approach. The comparative method was used as a main.

As part of the modernization of the education system, the transition to the use of modern teaching methods and technologies aimed at the continuous development and further improvement of communication skills and motivation should be ensured. Education can be considered as a system of humanitarian technologies that serves as a sphere of socio-humanitarian creativity, when self-actualization, emotional stability and selfdevelopment take place. These technologies include technology for developing critical thinking and reflexive learning.

Any change in a person's life, even minor, situational, requires adaptive readiness in the form of openness to experience, and efforts to coordinate external and internal instances. In the process of adaptation to the new educational environment, there is a change in the system of emotional and evaluative relations of a person to himself and the surrounding world, which not only expresses the internal "subjective world" of the individual, but is realized or manifested in an external fact.

The development of personality in this interpretation is generally considered as the process of entering a new social environment and integration in it. Three main phases of this process were identified:

- the adaptation phase (which involves the assimilation of existing values and norms and mastering the appropriate means and methods of activity);

the phase of individualization (as a result of the contradiction between the need to be "like everyone else" and the desire to stand out from the background);

the integration phase (as a connection with the desire to be represented with their own characteristics and differences, as well as the need of the community to accept the individual).

Self-actualization and self-realization of the individual must be combined with its adaptation, individualization and integration. Self-actualization and self-realization have a certain similarity to the processes of individualization, but they have a different quality: just to differ is not a aim, but to do it due to professional, personal or spiritual achievements, a system of relationships - is the main thing in the acmeological understanding.

E-learning is a new approach, new technologies that can create a favorable environment for self-development, when the individual acquires independence and autonomy, that is, individualization and socialization are interrelated parts of a single process of personal development.

From the acmeological point of view, personality develops in two areas - potential and actual. The sphere of potential includes: socio-psychological features; abilities; social opportunities of the educational environment that can be used for personal development.

The relevant areas are:qualitatively newly transformed potential; external manifestations of the really functioning. Thus, the person's development can be progressive, and perhaps harmonious, if it is carried out in both areas, and not in isolation. However, in acmeology, the potential of the individual is considered from its own position - as a system of constantly replenished and renewable resources. Digital technologies, which are actively and rapidly developing in the context of scientific and technological progress, can have a serious impact on the upbringing and development of the individual, help both in the educational process and beyond it [16]. For example, they are needed when organizing scientific work of students. At the same time, they can be used both for consultations and discussion of preliminary versions of scientific papers, and can be, for example, applied to improve knowledge and skills, characterological properties, etc., which is associated with personal and professional development. The renewable part of the potential of the individual now depends mainly on the subject itself and to a much lesser extent on society or the state, which now does not have a humanistic-oriented policy and ideology.

Digital technologies are of particular importance when organizing students' team work in remote mode, since they allow to take into account the most convenient time for everyone, exchange any materials, discuss them, ideas, conduct brief surveys and even vote for making appropriate decisions, etc.

The coronavirus pandemic has prompted a request to monitor digital technologies application by educational institutions. So, in particular, to assess the use of digital educational technologies in the educational process, a corresponding index can be used - a comprehensive index of distance technologies application in the educational process (further CIDTAEP = $\mathrm{W} 1 * \mathrm{x} 1+\mathrm{W} 2 * \mathrm{x} 2+\ldots .+\mathrm{Wn} * \mathrm{Xn}$, where

$\mathrm{W}$-percentage of the corresponding element

$\mathrm{X}$-this is the value of the corresponding element

$\mathrm{n}-\mathrm{a}$ number of included elements

According to the authors' mind, this formula can be modified for each country and even for each training area, taking into account the relevant features as much as possible. Potential evaluation criteria may include the following: the use of social networks, online courses of the relevant university on certain issues of the taught disciplines, visual instructions and guidelines for the implementation of various works provided for in the 
curriculum (term papers, final qualifying works, essays, etc.).

It is important to note that the social networks application has a great positive value in the context of student consultations. In particular, the social network "Vkontakte" allows to create very convenient visually and instrumentally communities and joint chats, where students can quickly ask questions and get answers (see picture 1). At the same time, communities have the opportunity to post various materials (task collections, answers to the most frequently asked questions, a list of questions for preparing for the interim certification, select the discussion of the most difficult tasks as a separate dialog), organize an online video broadcast and provide access to it for members of the relevant community after the its conducting.

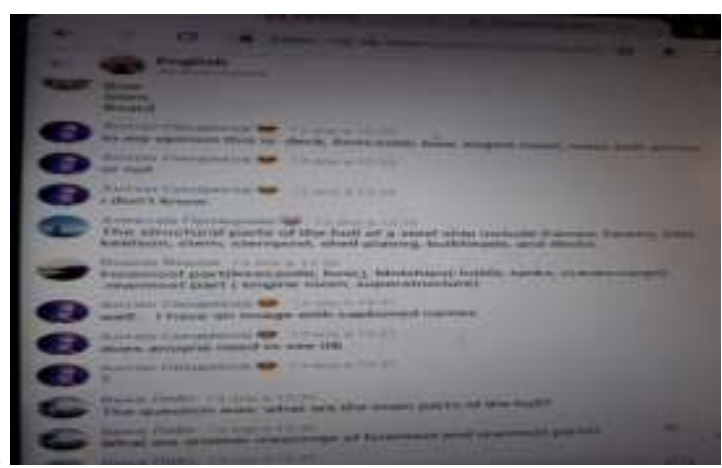

Figure 1 Screen of foreign language classes in the social network "Vkontakte"

In order to increase the interactivity of the educational process and objective control providing of students' knowledge, it may be recommended to use the "Kahoot" service. The teacher can create test tasks of different types (including those with several correct answers), setting their own "cost in points" for each question (thus maneuvering based on the complexity of the tasks). While using this system an advantage will be associated with the lack of subjectivity in evaluating students' knowledge.

\section{DISCUSSION OF THE RESULTS}

Among the possible disadvantages and limitations is the lack of an Internet connection on the teaching device or staff (the latter is relevant if the lesson is held remotely and the research and teaching staff shares the screen with students (if the speed is not high enough, both on the sending and receiving sides, the information may not be transmitted or transmitted in very low resolution).

After testing, the lecturer is able to use the reports provided by the system for uploading, identify problem blocks and repeat this material at the next (one of the next) classes or in preparation for the lesson. At the same time, it is important to use this formula to compare institutions and then build appropriate ratings and encourage rating leaders. The results obtained can also be used as scientific and methodological recommendations in providing the effectiveness of the adaptation process in the transition to distance learning.

The development of complex individual abilities is usually carried out in the process of learning, self-study and professional activity. But it should be remembered that this can be done individually in the process of using acmeological technologies or using acmeological training. It cannot completely replace humanitarian technologies for the integral development of the individual, because feedback, dialogue/communication between all participants of the communication process are required.

The main pedagogical purpose of the information technologies application is the self-development and selfrealization of persons. Active use of Internet technologies, telecommunication means in the educational process helps to facilitate learning and speed up the educational process. Among the existing information technologies the most popular are the following:

1. Electronic conference (computer conferences, allow to receive the texts of messages on the monitor of the user's computer transmitted by the participants of the "conference", located at different distances from each other).

2. Teleconference and video phone, which provide twoway communication between the teacher and students.

In the context of electronic conference and teleconference it is possible to apply technology visualization of the educational information: mind map (mental map, chart, links, map of thoughts, associative map, mind map), conducting brainstorming sessions, preparation of trees of concepts, technology, critical thinking, clusters, infographics, scribing and the technology of asking questions: the technique of asking questions "6Why", cross-discussion and others.

\section{CONCLUSION}

This process of personal self realization development by means of information technologies application is accompanied by significant changes in the pedagogical theory and practice of the educational process, associated with the introduction of adjustments to the content of learning technologies that should be adequate to modern technical capabilities, and contribute to the harmonious person's adaptation to the information environment. At the same time, it is important to warn against actively replacing intramural learning with distance learning. At the same time, digital technologies and interaction in remote mode can significantly improve the quality of the educational process in full-time format due to the ability to diversify the content and formats of their conduct.

Scientific and methodological recommendations and conclusions obtained on the basis of the theoretical analysis can be applied in order to provide improving the effectiveness of the adaptation process in the transition to distance learning.

The direction for future research may be represented be the investigation of effective conditions for person's socio- 
practice and design. Cambridge journal of education. v.

psychological adaptation in the new educational environment, taking into accounts both group and individual aspect.

\section{REFERENCES}

[1] V.V. Gritsenko, Theoretical bases of research of socio-psychological adaptation of a person / group in a new socio - and ethno-cultural environment: problems of social psychology of a person: Interuniversity collection of scientific work. Saratov, 2005, t. 2. pp. 19

[2] V.I. Panov, Psychodidactics of educational systems: theory and practice. Saint Petersburg, 2007, pp. 71

[3] I.V. Balynin., A.G. Mikhaylova, N.N. Nizhneva, Promote Development of Knowledge Intensive Activities on the Basis of Improving Management Training by Means of Acmeological Approach// Advances in Social Science, Education and Humanities Research, / 2nd International Scientific Conference on New Industrialization: Global, National, Regional Dimension (SICNI 2018), volume 24, pp.302-306 https://www.atlantis-press.com/proceedings/sicni-18 https://www.atlantis-press.com/proceedings/sicni$\underline{18 / 55911856}$

[4] A.A. Rean, Acmeology of a personality. Psikhologicheskiı̌ zhurnal. May 2000. 21(3), pp. 94-95

[5] Jacqueline Limoges, Kim Jagos, The Influences of Nursing Education on the Socialization and Professional Working Relationships of Canadian Practical and Degree Nursing Students: A Critical Analysis. Nurse education today, July 2015.

[6] R. M. Shaminov, A conference on social psychology of personality and acmeology, Voprosy psikhologii, 2014, v.6. pp.158-161

[7] S. Ahuja, D. Yadav, Effect of digital pedagogy interventions in rural areas. Mier-journal of educational studies trends and practices, V.9 Issue 2, pp. 227-240

[8] Y. Tabesh, Digital Pedagogy in Mathematical Learning. Invited lectures from the 13th International congress on mathematical education. ICME-13 Monographs, pp. 669-678

[9] E. Howell, Obstacles to digital, multimodal pedagogy in rural high schools. Writing \& pedagogy. v.10, Issue 1-2, pp. 297-321

[10] N. Kucirkova, T. Cremin, Personalised reading for pleasure with digital libraries: towards a pedagogy of
48, Issue 5, pp. 571-589

[11] L. McNeil, Implementing digital game-enhanced pedagogy: Supportive and impeding language awareness and discourse participation phenomena, RECALL. V. 32. Issue 1. pp. 106-124

[12] J. Sargent, A. Casey, Flipped learning, pedagogy and digital technology: Establishing consistent practice to optimise lesson time. European physical education review, v. 26. Issue 1. pp. 70-84

[13] C. Blundell, K.T. Lee, S. Nykvist, Moving beyond enhancing pedagogies with digital technologies: Frames of reference, habits of mind and transformative learning, Journal of research on technology in education, v. 52, Issue 2, pp. 178-196

[14] M. Dorofeyev, M. Kosov, V.Ponkratov, A. Masterov, A. Karaev, M. Vasyunina, Trends and prospects for the development of blockchain and cryptocurrencies in the digital economy, European Research Studies Journal, 2018, 21. 3, pp. 429-445.

[15] I.V. Balynin, A.G. Mikhaylova, N.N. Nizhneva, Information technology application to improve future professionals' financial literacy. Proceedings of the International Scientific and Practical Conference on Digital Economy (ISCDE 2019). Atlantis Press. December 2019. https://doi.org/10.2991/iscde19.2019 .48 https://www.atlantispress.com/proceedings/iscde-19/125924602 